\title{
Effects of continuous rate infusion of butorphanol in isoflurane-anesthetized calves ${ }^{1}$
}

\author{
Marcelo Augusto de Araújo ${ }^{I}$, Verônica Batista de Albuquerque ${ }^{\mathrm{II}}$, Maurício Deschk ${ }^{\mathrm{III}}$, Thomas Alexander Trein ${ }^{\mathrm{IV}}$, Fabrício de Oliveira \\ Frazíliov, Paulo Sergio Patto dos Santos ${ }^{\mathrm{VI}}$
}

DOI: http://dx.doi.org/10.1590/S0102-86502014000700009

IVeterinary Medical, Faculty of Veterinary Medicine and Animal Science, Federal University of Mato Grosso do Sul (UFMS), Campo Grande-MS, Brazil. Conception, design, intellectual and scientific content of the study; technical procedures; manuscript writing.

IIPhD, Associate Professor, Department of Veterinary Medicine, Faculty Integrated, Campo Mourao-PR, Brazil. Acquisition of data, technical procedures, manuscript writing.

IIIFellow PhD degree, Postgraduate Program in Animal Science, Faculty of Veterinary Medicine, São Paulo State University (UNESP), Araçatuba-SP, Brazil. Acquisition of data, technical procedures.

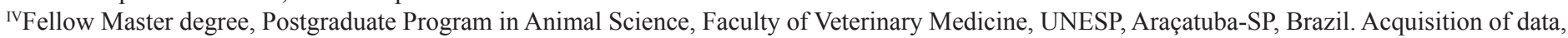
Responsible for English language.

vPhD, Associate Professor, Department of Veterinary Medicine, Surgery and Anesthesiology, Faculty of Veterinary Medicine and Animal Science, UFMS, Campo Grande-MS, Brazil. Conception, design, intellectual and scientific content of the study.

${ }^{\mathrm{V}} \mathrm{PhD}$, Assistant Professor, Department of Clinical, Surgery and Animal Reproduction, Faculty of Veterinary Medicine, UNESP, Araçatuba-SP, Brazil. Statistical analysis, critical revision.

\section{ABSTRACT}

PURPOSE: To assess the hemodynamic changes and bispectral index (BIS) following administration of a continuous rate infusion (CRI) of butorphanol in isoflurane-anesthetized calves.

METHODS: Eight calves weighing $110 \pm 12 \mathrm{~kg}$ were included in the study. Anesthesia was induced with $5 \%$ isoflurane in $\mathrm{O}_{2}$ delivered via face mask and maintained with end-tidal concentration of $1.4 \%$. IPPV was set to a peak inspiratory airway pressure of $15 \mathrm{cmH}_{2} \mathrm{O}$ and respiratory rate of six breaths minute ${ }^{-1}$. Forty minutes after the start of anesthetic maintenance, $0.1 \mathrm{mg} \mathrm{kg}^{-1} \mathrm{butorphanol}$ was administered intravenously, followed by a CRI of $20 \mu \mathrm{g} \mathrm{kg}^{-1}$ minute-1. Hemodynamic variables and BIS were recorded before butorphanol administration (T0), and at 10, 20,40 and 80 minutes following the CRI. Anesthesia was discontinued after the last recording and the calves were allowed to recover. The time to sternal recumbency (SRE) and standing (ST) were evaluated.

RESULTS: There were no significant differences between the moments in all hemodynamic variables and BIS. The time to SRE and ST was $9 \pm 5$ and $14 \pm 7$ minutes, respectively.

CONCLUSION: The continuous rate infusion did not produce clinically relevant changes in hemodynamic or bispectral index values compared to baseline in mechanically ventilated and unstimulated calves anesthetized at $1.4 \%$ isoflurane.

Key words: Hemodynamics, Intermittent Positive-Pressure Ventilation. Butorphanol. Anesthesia, Inhalation. Cattle. 


\section{Introduction}

Inhalation anesthesia is associated with a dose-dependent cardiovascular and respiratory depression ${ }^{1}$. Balanced anesthesia is often used to decrease inhalant anesthetic requirement, thereby limiting cardiovascular depressant effects and providing additional analgesia ${ }^{2,3}$.

Butorphanol is an opioid agonist-antagonist and as such is a competitive antagonist at the $\mu$ receptor and an agonist at the $\kappa$ receptor. This mixed agonistic-antagonist activity results in analgesia and is less likely to induce respiratory depression, compared with pure $\mu$ agonistic activity ${ }^{4}$, and contributes to the management of balanced anesthesia ${ }^{5,6}$.

Opioids have been extensively studied and used in dogs, cats and horses ${ }^{6-8}$. However, research evaluating opioid-induced analgesia and hemodynamic effects in bovines is still scarce.

Clinical assessment of depth of anesthesia in animals requires the anesthesia provider to evaluate a variety of autonomic and motor reflexes, as well as changes in heart rate and arterial blood pressure. Although they are simple to be obtained, these clinical signs can be an imprecise method for judging the degree of central nervous system (CNS) depression and analgesic requirements. Objective methods for assessing anesthetic depth and analgesic requirements that employ processed EEG data, such as BIS, have been investigated ${ }^{9}$.

Although BIS was originally designed for human subjects, studies have demonstrated its usefulness in anesthetic procedures in other species ${ }^{10-15}$. To the author's knowledge, limited data characterizing BIS in bovines have been published.

The purpose of this study was to investigate the bispectral index, hemodynamic effects and recovery in isofluraneanesthetized calves submitted to an intravenous continuous rate infusion (CRI) of $20 \mu \mathrm{g} \mathrm{kg}^{-1}$ minute $^{-1}$ of butorphanol during mechanical ventilation. The authors hypothesized that a CRI of butorphanol would not cause clinically relevant hemodynamic, bispectral index and recovery changes.

\section{Methods}

The study and experimental design were approved by the local Institutional Animal Care and Use committee (005150). A total of eight male Holstein calves, aged $9 \pm 1$ months and weighing $110 \pm 12 \mathrm{~kg}$, were used in the study. All calves were considered healthy on the basis of physical examination and complete blood count (CBC). Food was withheld for 24 and water for 12 hours prior to the experimental procedure.
Before anesthesia, the calves were restrained in left lateral recumbency and a 16-gauge catheter (Intracath, BD, Juiz de Fora, Brazil) was inserted into the right jugular vein for butorphanol administration. Afterwards, a 22-gauge catheter (Insyte, BD, Juiz de Fora, Brazil) was inserted into a branch of the left auricular artery to assess arterial pressure and to obtain arterial blood samples for gas analysis.

In all animals, anesthesia was induced with 5\% isoflurane (Isoforine, Cristalia, São Paulo, Brazil) in oxygen administered via a face mask. Subsequently, the tracheas were intubated and the animals were positioned in right lateral recumbency. Anesthesia was maintained with isoflurane at a constant end-tidal concentration of $1.4 \%$ (MAC $1.27 \%)^{16}$ diluted in an oxygen flow of $15 \mathrm{mLkg}^{-1}$ minute $^{-1}$, using a calibrated vaporizer(HB, São Paulo, Brazil) and a rebreathing circuit (Conquest Big, HB, São Paulo, Brazil).

Intermittent positive pressure ventilation (IPPV) was adjusted at the beginning of the procedure to a peak inspiratory airway pressure of $15 \mathrm{cmH}_{2} \mathrm{O}$ and respiratory rate (fr) of 6 breaths minute $^{-1}$ using a mechanical ventilator (Conquest Big, HB, São Paulo, Brazil).

A period of 40 minutes was awaited to guarantee stabilization of the isoflurane concentration prior to drug administration and data collection. During this perioda SwanGanz thermodilution catheter $(7 \mathrm{~F}, 110 \mathrm{~cm}$, Edwards lifesciences, São Paulo, Brazil) was inserted into the pulmonary artery.

The Swan-Ganz catheter was advanced into the left jugular vein through a catheter introducer (Intro-Flex, 8.5F, Edwards Lifesciences, São Paulo, Brazil). Proper positioning of the distal tip of the Swan-Ganz catheter in the pulmonary artery was determined by observing the characteristic waveform on the monitor (Dixtal 2020, invasive pressure module, Manaus, Brazil). The catheter was connected to a cardiac output module and a monitor (Dixtal 2020, Manaus, Brazil), and cardiac output was determined by the thermodilution technique. The computation constant was adjusted for a 7F Swan-Ganz catheter, injection temperature ranging from 0 to $5^{\circ} \mathrm{C}$ and injection volume of 10 $\mathrm{mL}$ of $0.9 \%$ sodium chloride. Central venous pressure (CVP), mean pulmonary arterial pressure (MPAP), pulmonary arterial occlusion pressure (PAOP) and central temperature (CT) were measured using the Swan-Ganz catheter connected to an invasive pressure module.

Systolic, diastolic and mean arterial pressures (SAP, DAP and MAP) were measured from a 22-gauge catheter (Insyte; BD, Juiz de Fora, Brazil) inserted into a branch of the left auricular artery and connected to a transducer. The level of the sternum was considered the zero pressure point for 
calibration. Heart rate (HR) was obtained by a computerized electrocardiograph (Dixtal 2020, Manaus, Brazil), adjusted to lead II. Oxyhemoglobin saturation $\left(\mathrm{SpO}_{2}\right)$ was obtained by the monitor (Dixtal 2020, Manaus, Brazil) with the sensor placed on the tongue.

Cardiac index (CI), systemic (SVRI) and pulmonary (PVRI) vascular resistance index and stroke volume index (SI) were calculated using the following formulae: $\mathrm{CI}=\mathrm{CO} / \mathrm{BSA}$, where $\mathrm{CO}=$ cardiac output in $\mathrm{L}_{\text {minute }}{ }^{-1}$ and BSA (body surface area in $\left.\mathrm{m}^{2}\right)=$ weight $^{0.6667} / 10$; SVRI $=[(\mathrm{MAP}-\mathrm{CVP}) / \mathrm{CI}] \times 80$; $\mathrm{PVRI}=[(\mathrm{mPAP}-\mathrm{PAOP}) / \mathrm{CI}] \times 80 ; \mathrm{SI}=\mathrm{SV} / \mathrm{BSA}$, where $\mathrm{SV}=$ $\mathrm{CO} \times 1000 / \mathrm{HR}$.

End-tidal concentration of isoflurane (E'Iso) and endtidal carbon dioxide tension $\left(\mathrm{PE}^{\prime} \mathrm{CO}_{2}\right)$ were monitored using a digital gas analyzer (Dixtal 2020; gas analyzer module, Manaus, Brazil). The assessment of inspired oxygen tension $\left(\mathrm{FIO}_{2}\right)$, was performed by the monitor (Dixtal 2020; ventilatory module, Manaus, Brazil). Samples of these variables were continuously aspirated from a sample line connected between the endotracheal tube and the breathing circuit.

Arterial blood samples $(0.6 \mathrm{~mL})$ were anaerobically collected into an EDTA syringe (A-Line; BD, Juiz de Fora, Brazil) and analysed for $\mathrm{pH}$, arterial partial pressure of carbon dioxide $\left(\mathrm{PaCO}_{2}\right)$, arterial partial pressures of oxygen $\left(\mathrm{PaO}_{2}\right)$, alveolar partial pressure of oxygen $\left(\mathrm{PAO}_{2}\right)$, base deficit (BD), bicarbonate concentration $\left(\mathrm{HCO}_{3}^{-}\right)$, which was performed using a blood gas analyzer (Roche Omni C; Roche Diagnostics, Germany).

Bispectral index was evaluated using the monitor (DX-2020; bispectral index module, Dixtal, Manaus, Brazil) connected to the BIS recording electrodes (BIS Quatro Sensor, Aspect Medical System, Norwood, USA). The heads of the animals were shaved and defatted with diethyl ether in order to place the electrodes appropriately. Then, the electrodes were positioned in the frontal-temporal region, which is an adaptation from Campagnol et al. ${ }^{17}$. Electrode 1 was placed midline on the frontal bone region, immediately above the eye line. Electrodes 2 and 4 were placed at an angle of $15^{\circ}$ to $30^{\circ}$ to the transverse plane. Electrode 3 was placed on the region of the temporal bone, cranial to the base of the left ear. The impedance of the electrodes was automatically checked by the BIS monitor and rejected if less than $7.5 \mathrm{k} \Omega$. Artifacts were identified by applying high and low frequency filters that were adjusted to 70 and $2 \mathrm{~Hz}$, respectively. The BIS number was hand recorded during 1 minute (one number per second) for each time measurement and a single BIS value was determined by averaging all the recorded values. The signal quality index (SQI), suppression ratio (SR) and electromyography (EMG) were also recorded to verify the reliability of the BIS value obtained.

After the preparation period, the animals received 0.1 $\mathrm{mg} \mathrm{kg}{ }^{-1}$ of butorphanol (10 $\mathrm{mg} \mathrm{mL}^{-1}$, Torbugesic; Fort Dodge, Campinas, Brazil) intravenously followed by a CRI of butorphanol at $20 \mu \mathrm{g} \mathrm{kg}^{-1}$ minute $^{-1}$, infused through a syringe pump (ST680, Samtronic, São Paulo, Brazil).

The first recordings were performed immediately before the administration of butorphanol (T0), and at 10, 20, 40 and 80 minutes after the start of CRI (T10, T20, T40 and T80). After the last recording, anesthesia and CRI were discontinued and the animals were allowed to recover. The time when the vaporizer was turned off was taken as the reference start point for recording time to sternal recumbency (SRE) and standing (ST).

\section{Statistical analysis}

For statistical analysis data are expressed as means and standard deviation $(\mathrm{x} \pm \mathrm{SD})$. Normality check of the variables was performed using Shapiro-Wilk test (BioStat 5.8.4 professional; Analyst Soft, Chicago, USA). Normal data (parametric) were examined with repeated measures analysis of variance (ANOVA), and post-hoc Bonferroni test for multiple comparisons if significance was detected. Data that failed the normality test (non parametric) were analyzed using a Friedman test, followed by post-hoc Dunn test. Data regarding BIS were examined with One-way ANOVA and post-hoc Bonferroni test for multiple comparisons between treatments and times. Data of recovery were evaluated with Student's t test. Significance was defined at $p<0.05$. Tests were performed using computer software (Graphpad InStat 3; Graphpad Software Inc., San Diego, USA).

\section{Results}

There were no significant differences between the time points in all hemodynamic and blood gas analysis variables (Tables 1 and 2). 
TABLE 1 - Mean \pm standard deviation of hemodynamic parameters of eight calves anesthetized with isoflurane and treated with a continuous infusion of butorphanol at a rate of $20 \mu \mathrm{g} \mathrm{kg}^{-1}$ minute ${ }^{-1}$.

\begin{tabular}{|c|c|c|c|c|c|}
\hline \multirow{2}{*}{ Parameter } & \multicolumn{5}{|c|}{ Times } \\
\hline & TO & T10 & T20 & T40 & T80 \\
\hline $\begin{array}{c}\text { Heart rate } \\
{\text { (beats } \text { minute }^{-1} \text { ) }}^{\text {Hean }}\end{array}$ & $75 \pm 16$ & $76 \pm 17$ & $78 \pm 18$ & $79 \pm 18$ & $76 \pm 14$ \\
\hline $\begin{array}{l}\text { Systolic arterial pressure } \\
(\mathrm{mm} \mathrm{Hg})\end{array}$ & $114 \pm 22$ & $113 \pm 22$ & $119 \pm 22$ & $124 \pm 23$ & $127 \pm 21$ \\
\hline $\begin{array}{l}\text { Mean arterial pressure } \\
(\mathrm{mm} \mathrm{Hg})\end{array}$ & $89 \pm 20$ & $88 \pm 19$ & $94 \pm 17$ & $100 \pm 20$ & $102 \pm 18$ \\
\hline $\begin{array}{l}\text { Diastolic arterial pressure } \\
\text { (mm Hg) }\end{array}$ & $68 \pm 18$ & $67 \pm 16$ & $73 \pm 14$ & $77 \pm 17$ & $79 \pm 15$ \\
\hline $\begin{array}{l}\text { Cardiac Index } \\
\left(\mathrm{mL} \mathrm{m}^{2} \text { minute }^{-1}\right)\end{array}$ & $5.77 \pm 1.05$ & $5.81 \pm 1.45$ & $5.68 \pm 1.27$ & $5.68 \pm 1.29$ & $6.00 \pm 1.30$ \\
\hline $\begin{array}{c}\text { Mean pulmonary arterial pressure } \\
\text { (mm } \mathrm{Hg})\end{array}$ & $15 \pm 3$ & $14 \pm 3$ & $15 \pm 3$ & $16 \pm 3$ & $15 \pm 2$ \\
\hline $\begin{array}{l}\text { Pulmonary arterial occlusion pressure } \\
\text { (mm Hg) }\end{array}$ & $4 \pm 2$ & $3 \pm 3$ & $4 \pm 3$ & $5 \pm 3$ & $4 \pm 3$ \\
\hline $\begin{array}{l}\text { Central venous pressure } \\
(\mathrm{mm} \mathrm{Hg})\end{array}$ & $-1 \pm 2$ & $-2 \pm 3$ & $-1 \pm 2$ & $0 \pm 2$ & $0 \pm 2$ \\
\hline $\begin{array}{l}\text { Systemic vascular resistance index } \\
\left.\text { (dynes seconds } \mathrm{cm}^{-5} \mathrm{~m}^{2}\right)\end{array}$ & $1274 \pm 413$ & $1272 \pm 397$ & $1367 \pm 408$ & $1459 \pm 462$ & $1445 \pm 472$ \\
\hline $\begin{array}{l}\text { Pulmonary vascular resistance index } \\
\text { (dynes seconds } \mathrm{cm}^{-5} \mathrm{~m}^{2} \text { ) }\end{array}$ & $151 \pm 27$ & $154 \pm 31$ & $141 \pm 35$ & $155 \pm 38$ & $154 \pm 42$ \\
\hline $\begin{array}{l}\text { Stroke index } \\
\left(\mathrm{mL} \text { beat }{ }^{-1} \mathrm{~m}^{2}\right)\end{array}$ & $77 \pm 10$ & $79 \pm 10$ & $77 \pm 11$ & $76 \pm 13$ & $80 \pm 14$ \\
\hline $\begin{array}{c}\text { Oxyhemoglobin saturation } \\
(\%)\end{array}$ & $99 \pm 1$ & $99 \pm 1$ & $99 \pm 1$ & $99 \pm 1$ & $99 \pm 1$ \\
\hline $\begin{array}{l}\text { Inspired oxygen tension } \\
(\%)\end{array}$ & $90 \pm 4$ & $92 \pm 2$ & $93 \pm 3$ & $94 \pm 3$ & $94 \pm 2$ \\
\hline $\begin{array}{c}\text { End-tidal concentration of isoflurane } \\
(\%)\end{array}$ & $1.3 \pm 0.04$ & $1.4 \pm 0.10$ & $1.4 \pm 0.05$ & $1.4 \pm 0.08$ & $1.4 \pm 0.08$ \\
\hline $\begin{array}{l}\text { End-tidal carbon dioxide tension } \\
\text { (mm Hg) }\end{array}$ & $46 \pm 2$ & $46 \pm 5$ & $47 \pm 4$ & $47 \pm 4$ & $47 \pm 5$ \\
\hline $\begin{array}{c}\text { Central temperature } \\
\left({ }^{\circ} \mathbf{C}\right)\end{array}$ & $38.7 \pm 0.6$ & $38.5 \pm 0.7$ & $38.6 \pm 0.8$ & $38.6 \pm 0.9$ & $38.6 \pm 1.0$ \\
\hline
\end{tabular}

Means followed by different lower case letters in rows differ by Bonferroni test or Dunn ( $p>0.05)$.

Means followed by different upper case letters in columns differ by Bonferroni test or Dunn ( $p>0.05)$. 
TABLE 2 - Mean \pm standard deviation of blood gas analysis of eight calves anesthetized with isoflurane and treated with a continuous infusion of butorphanol at a rate of $20 \mu \mathrm{g} \mathrm{kg}^{-1}$ minute ${ }^{-1}$.

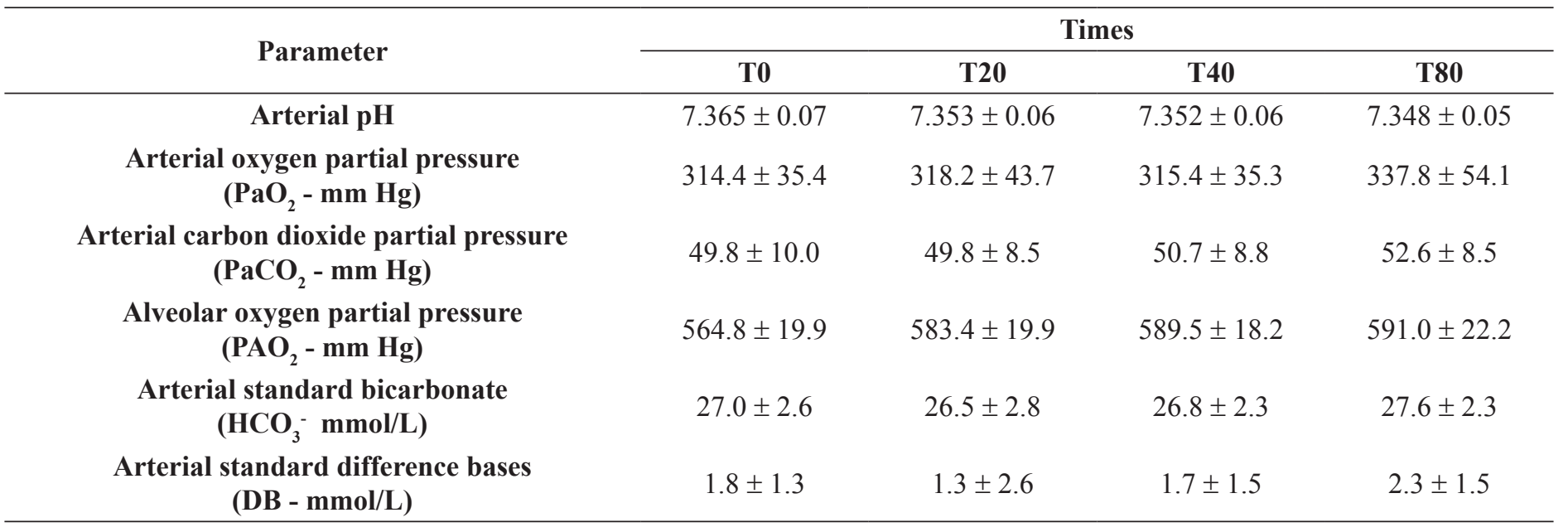

Means followed by different lower case letters in rows differ by Bonferroni test or Dunn ( $\mathrm{p}>0.05)$.

Means followed by different upper case letters in columns differ by Bonferroni test or Dunn ( $\mathrm{p}>0.05)$.

BIS recordings were always associated with $>90 \%$ signal quality index, suppression ratio of 0 and low electromyography activity. There was no difference when T0 was compared with other time points (Table 3).

TABLE 3 - Mean \pm standard deviation of bispectral index in eight calves anesthetized with isoflurane and treated with a continuous infusion of butorphanol at a rate of $20 \mu \mathrm{g} \mathrm{kg}^{-1}$ minute ${ }^{-1}$.

\begin{tabular}{cccccc}
\hline Parameter & \multicolumn{5}{c}{ Times } \\
\cline { 2 - 6 } & T0 & T10 & T20 & T40 & T80 \\
\hline BIS & $40 \pm 6^{\mathrm{a}}$ & $41 \pm 5^{\mathrm{a}}$ & $41 \pm 4^{\mathrm{a}}$ & $44 \pm 7^{\mathrm{a}}$ & $44 \pm 7^{\mathrm{a}}$ \\
\hline
\end{tabular}

Means followed by different lower case letters in rows differ by Bonferroni test or Dunn ( $\mathrm{p}>0.05)$.

Means followed by different upper case letters in columns differ by Bonferroni test or Dunn $(\mathrm{p}>0.05)$.

The times to sternal recumbency and standing position were $9 \pm 5$ and $14 \pm 7$ minutes, respectively. Quality of recovery was considered smooth in all animals.

\section{Discussion}

The use of an IV dose of $0.1 \mathrm{mg} \mathrm{kg}^{-1}$ of butorphanol was based on previous studies using the same opioid in ruminants ${ }^{14,18}$. Due to the lack of studies reporting the use of CRI of butorphanol in bovines, the rate used in this experiment was initially based in rates employed in horses Sellon et al. ${ }^{19}$, and adjusted to $20 \mu \mathrm{g} \mathrm{kg}^{-1}$ minute ${ }^{-1}$.

With regards to the experimental protocol, mask induction with isoflurane was used to avoid interference from the use of other drugs in the study results. Similarly, controlled ventilation was employed in order to maintain a stable plane of anesthesia and to reduce hemodynamic variations caused by high arterial concentrations of carbon dioxide ${ }^{20,21}$.

The results of hemodynamic variables are similar to those reported by Garcia-Pereira et al. ${ }^{14}$. Similar to the results obtained in this study, the authors also observed no changes in cardiovascular variables in isoflurane-anesthetized alpacas submitted to IV administration of butorphanol at a dose of 0.1 $\mathrm{mg} \mathrm{kg}{ }^{-1}$. On the other hand, in the study conducted by Keegan et al. ${ }^{22}$, IV administration of butorphanol at a dose of $0.2 \mathrm{mg} \mathrm{kg}^{-1}$ in sevoflurane-anesthetized calves was associated with a decrease in HR and arterial pressure. We believe these observations might have been influenced by the higher dose used in the study.

A limitation of the study was not to perform a control group, in order to show potential temporal changes in the hemodynamic variables. Nevertheless, the temporal effects of anesthesia maintained with isoflurane has been observed in previous studies

and were similar to those seen in the present study ${ }^{23-25}$. As a consequence, the results show that a continuous infusion of butorphanol did not cause significant hemodynamic changes in the present study.

The BIS values observed in the current study ranged between 40 and 44 . These values were lower than those found by Garcia-Pereira et al. ${ }^{14}$, in a study with alpacas anesthetized with a constant E'Iso of $1.75 \%$ associated with butorphanol, $0.1 \mathrm{mg}$ $\mathrm{kg}^{-1} \mathrm{IV}$, which ranged between 52 and 57. Although the mean BIS values obtained in the present study seemed consistent with values associated with surgical anesthesia in humans, more specific studies are required in order to validate BIS values in bovines ${ }^{14}$. 
Following termination of anesthetic maintenance and CRI, all calves recovered uneventufully and no adverse effects were observed at recovery. Nevertheless, recovery time was greater than that observed by Cantalapietra et al. ${ }^{16}$, which reported a mean of 4.6 minutes to sternal recumbency and 6.7 minutes to standing position in cattle anaesthetized with $1 \mathrm{MAC}$ of isoflurane for 90 minutes.

\section{Conclusion}

The rate of continuous rate infusion of butorphanol for 80 minutes did not produce any clinically relevant alterations in hemodynamic or bispectral index values compared to baseline in mechanically ventilated, unstimulated calves anesthetized at E'Iso of $1.4 \%$. In addition, recovery was rapid and uneventful.

\section{References}

1. Grosenbaugh DA, Muir WW. Cardiorespiratory effects of sevoflurane, isoflurane, and halothane anesthesia in horses. Am J Vet Res. 1998 Jan;59(1):101-6. PMID: 9442252.

2. Ringer SK, Kalchofner K, Boller J, Fürst A, BettschartWolfensberger R. A clinical comparison of two anaesthetic protocols using lidocaine or medetomidine in horses. Vet Anaesth Analg. 2007 Jul;34(4):257-68. doi:10.1111/j.1467-2995.2006.00321.x.

3. Valverde A. Balanced anesthesia and constant-rate infusions in horses. Vet Clin North Am Equine Pract. 2013 Apr;29(1):89-122. doi: 10.1016/j.cveq.2012.11.004.

4. Gillis JC, Benfield P, Goa KL. Transnasal butorphanol: a review of its pharmacodynamic and pharmacokinetic properties, and therapeutic potential in acute pain management. Drugs. 1995 Jul;50(1):157-75. doi:10.2165/00003495-199550010-00010.

5. Caure S, Cousty M, Tricaud C. Effects of adding butorphanol to a balanced anaesthesia protocol during arthoroscopic surgery in horses. Vet Rec. 2010 Mar;166(11): 324-8. doi: 10.1136/vr.b4799.

6. Santos PSP, Nunes N, Souza AP, Rezende ML, Nishimori CT, Paula DP, Ferro Lopes PC. Hemodynamic effects of butorphanol in desflurane-anesthetized dogs. Vet Anaesth Analg. 2011 Sep;38(5):467-74. doi: 10.1111/j.1467-2995.2011.00644.x.

7. Hofmeister EH, Mackey EB, Trim CM. Effect of butorphanol administration on cardiovascular parameters in isofluraneanesthetized horses - a retrospective clinical evaluation. Vet Anaesth Analg. 2008 Jan;35(1):38-44. PMID: 17696970.

8. Warne LN, Beths T, Holm M, Bauquier SH. Comparison of perioperative analgesic efficacy between methadone and butorphanol in cats. J Am Vet Med Assoc. 2013 Sep;243(6):844-50. doi: 10.2460/javma.243.6.844.

9. Henao-Guerrero PN, Mcmurphy R, Kukanich B. Hodgson DS. Effect of morphine on the bispectral index during isoflurane anesthesia in dogs. Vet Anaesth Analg. 2009 Mar;36(2):133-43. doi: 10.1111/j.1467-2995.2008.00440.x.

10. Antognini JF, Wang XW, Cartens E. Isoflurane anaesthetic depth in goats monitored using the bispectral index of the electroencephalogram. Vet Res Commun. 2000 Sep;24(6):361-70. PMID: 11014605.

11. Martin-Cancho M, Lima JR, Luis L, Crisóstomo V, Ezquerra LJ, Carrasco MS, Usón-Gargallo J. Bispectral index, spectral edge frequency $95 \%$, and median frequency recorded for various concentration of isoflurane and sevoflurane in pigs. Am J Vet Res. 2003 Jul;64(7):866-73. doi:10.2460/ajvr.2003.64.866.

12. Lamont LA, Greene SA, Grimm KA, Tranquilli WJ. Relationship of feline bispectral index to multiples of isoflurane minimum alveolar concentration. Comp Med. 2005 Jul;55(3):269-74. PMID: 16089176.

13. Bleijenberg EH, van Oostrom H, Akkerdaas LC, Doornenbal A, Hellebrekers LJ. Bispectral index and the clinically evaluated anaesthetic depth in dogs. Vet Anaesth Analg. 2011 Nov;38(6):53643. doi: 10.1111/j.1467-2995.2011.00651.x.

14. Garcia-Pereira FL, Greene AS, keegan RD, McEwen MM, Tibary A. Effects of intravenous butorphanol on cardiopulmonary function in isoflurane-anesthetized alpacas. Vet Anesth Analg. 2007 Jul;34(4):269-74. doi: 10.1111/j.1467-2995.2006.00325.x.

15. Creighton CM, Lemke KA, Lamont LA, Horney BS, Riley CB. Comparison of the effects of xylazine bolus versus medetomidine constant rate infusion on cardiopulmonary function and depth of anesthesia in horses anesthetized with isoflurane. J Am Vet Med Assoc. 2012 Apr;240(8):991-7. doi: 10.2460/javma.240.8.991.

16. Cantalapietra AG, Villanueva B, Pereira JL. Anaesthetic potency of isoflurane in cattle: Determination of the minimum alveolar concentration. Vet Anaesth Analg. 2000 Jan;27(1):22-6. doi: 10.1046/j.1467-2995.2000.00002.x

17. Campagnol D, Teixeira Neto FJ, Monteiro ER, Beier LS, Aguiar AJA. Use of bispectral index to monitor depth of anesthesia in isoflurane-anesthetized dogs. Am J Vet Res. 2007 Dec;68(12):13007. doi: 10.2460/ajvr.68.12.1300.

18. Carroll GL, Boothe DM, Hartsfield SM, Martinez EA, Spann AC, Hernandez A. Pharmacokinetics and pharmacodynamics of butorphanol in llamas after intravenous and intramuscular administration. J Am Vet Med Assoc. 2001 Nov;219(9):1263-7. PMID: 11697372.

19. Sellon DC, Monroe VL, Roberts MC, Papich MG. Pharmacokinetics and adverse effects of butorphanol administered by single intravenous injection or continuous intravenous infusion in horses. Am J Vet Res. 2001 Feb;62(2):183-9. doi: 10.2460/ajvr.2001.62.183.

20. Wagner AE, Bednarski RM, Muir WW. Hemodinamyc effects of carbon dioxide during intermittent positive-pressure ventilation in horses. Am J Vet Res 1990 Dec;51(12):1922-8. PMID: 2128172.

21. Day TK, Gaynor JS, Muir WW, Bednarski RM, Mason DE. Blood gas values during intermittent positive pressure ventilation and spontaneous ventilation in 160 anesthetized horses positioned in lateral and dorsal recumbency. Vet Surg 1995 May-Jun;24(3):266-76. PMID: 7653042.

22. Keegan RD, Valdez RA, Greene SA, Knowles DK. Cardiovascular effects of butorphanol in sevoflurano-anesthetized calves. Vet Anesth Analg. 2001;28(2):97-110. doi: 10.1111/j.1467-2987.2001.40-16.x.

23. Kerr CL, Windeyer C, Bouré LP, Mirakhur KK, McDonell W. Cardiopulmonary effects of administration of a combination solution of xylazine, guaifenesin, and ketamine or inhaled isoflurane in mechanically ventilated calves. Am J Vet Res. 2007;68(12):128793. doi: 10.2460/ajvr.68.12.1287.

24. Offinger J, Meyer H, Fischer J, Kästner SB, Piechotta M, Rehage J. Comparison of isoflurane inhalation anaesthesia, injection anaesthesia and high volume caudal epidural anaesthesia for umbilical surgery in calves; metabolic, endocrine and cardiopulmonary effects. Vet Anaesth Analg. 2012;39(2):123-36. doi: 10.1111/j.1467-2995.2011.00698.x.

25. Araújo MA, Dias BP, Bovino F, Deschk M, Rodrigues CA, Oliva, VNL, Rodrigues CA, Santos PS. Cardiovascular effects of a continuous rate infusion of lidocaine in calves anesthetized with xylazine, midazolam, ketamine and isoflurane. Vet Anesth Analg. 2014 Mar;41(2):145-52. doi: 10.1111/vaa.12102. 


\section{Correspondence:}

Fabrício de Oliveira Frazílio

Avenida Senador Filinto Muller, 2443

79074-460 Campo Grande - MS Brasil

Tel.: (55 67)8109-8094

fabricio.frazilio@ufms.br

Received: Feb 24, 2014

Review: April 22, 2014

Accepted: May 29, 2014

Conflict of interest: none

Financial source: none

${ }^{1}$ Research performed at Division of Operative Technique and Experimental Surgery, Department of Surgery, Federal University of Mato Grosso do Sul (UFMS), Campo Grande-MS, Brazil. 